\title{
Oxidative Stress in Newborn Erythrocytes
}

\author{
YAEL SHAHAL, ERIKA R. BAUMINGER, EHUD ZMORA, MIRIAM KATZ, DALIA MAZOR, \\ SARAH HORN, AND NAOMI MEYERSTEIN \\ Dr. Joseph Kaufmann Hematology Laboratory, Physiology Unit, Corob Research Center, Faculty of Health \\ Sciences, Ben Gurion University of the Negev, Beer Sheva and Racah Institute of Physics, Hebrew University, \\ Jerusalem and Neonatal Department and Obstetrics and Gynecology Department, Soroka University Center, Ben \\ Gurion University of the Negev, Beer Sheva, Israel
}

\begin{abstract}
Phenylhydrazine (PHZ) exposure is used to study in vitro red cell aging mechanisms dependent on $\mathrm{Hb}$ oxidation. The effect of $\mathrm{PHZ}$ on normal neonatal red blood cells was studied in unseparated blood and after separation into light and heavy cells. PHZ caused more extensive morphologic changes in neonatal than in adult red blood cells. PHZ exposure of neonatal cells caused less reduced glutathione depletion than in adult cells. Although we found the same total amount of oxidized $\mathrm{Hb}$ in both cells, a welldefined oxidation product of $\mathrm{Hb}$ was demonstrated by Mössbauer spectra only in neonatal cells. This oxidation product was not methemoglobin but a trivalent, high-spin iron compound. All neonatal cell populations were more sensitive to PHZ than were adult ones, as demonstrated by the presence of Heinz bodies at low PHZ concentration, which did not affect adult cells. These studies demonstrate greater sensitivity of neonatal cells to $\mathrm{PHZ}$ in all densityseparated populations. (Pediatr Res 29: 119-122, 1991)
\end{abstract}

\section{Abbreviations}

GOT, glutamate oxaloacetate transaminase

GSH, reduced glutathione

$\mathrm{HbF}$, fetal hemoglobin

PHZ, phenylhydrazine

RBC, red blood cell

SOD, superoxide dismutase

Neonatal RBC differ from adult RBC in several of their characteristics. Most of the intracellular $\mathrm{Hb}$ is $\mathrm{HbF}$, a highaffinity $\mathrm{Hb}$ adapted to intrauterine life (1). Most of the enzymatic activities in neonatal $\mathrm{RBC}$ are greater than those in adult $\mathrm{RBC}$ and may be attributed to their younger mean age (2). However, it is known that neonatal RBC have a shorter life-span $(2,3)$. The cause of this shortened survival time has not yet been clarified. Recently, red cell senescence in adults has been correlated with the oxidation of intracellular $\mathrm{Hb}$ to methemoglobin and hemichromes (4). Low et al. (4) have shown that exposure of normal cells to PHZ oxidizes the $\mathrm{Hb}$ to methemoglobin and hemichromes. These oxidized $\mathrm{Hb}$ products attach themselves to the intracellular portion of band 3 membrane protein, causing changes in surface antigenicity and increased IgG binding. Similar changes have been demonstrated in untreated cells containing pathologic $\mathrm{Hb}$, such as $\mathrm{Hb}$ Köln, known for its high affinity to oxygen and its lack of stability (5).

Our purpose was to assess the impact of oxidative stress,

Received June 27, 1990; accepted September 21, 1990

Correspondence: Naomi Meyerstein, M.D., Ph.D., Dr. Joseph Kaufmann Hematology Laboratory, Physiology Unit, Corob Research Center, Faculty of Health Sciences, Ben Gurion University, Beer Sheva, Israel. induced by low dose of PHZ, on neonatal erythrocytes, specifically: 1) to study $\mathrm{Hb}$ oxidation in neonatal and adult cells by two methods (measuring total oxidized $\mathrm{Hb}$ by spectrophotometry and identifying specific oxidation products by Mössbauer spectra) and 2) to see whether neonatal heavy cells, enriched with old cells, are more sensitive to oxidation than lighter and younger cells.

\section{MATERIALS AND METHODS}

Collection and preparation of blood samples. Blood samples were obtained from umbilical veins immediately after delivery. Newborn infants, whose mothers had experienced normal pregnancies, were all healthy and mature. Blood counts and glucose6-phosphate dehydrogenase activity were normal. Control studies were performed using blood drawn from healthy adult volunteers according to the conditions of the Helsinki Declaration. The blood was collected into heparinized tubes; the buffy coat and plasma were removed and the cells were washed three times in PBS, pH 7.4.

The cells were studied both as a whole, unseparated population and after separation on a Percoll gradient. The cells were separated into $10 \%$ high ("old") and 10\% low ("young") density cells, according to Ellory and Young (6).

The cells were exposed to $\mathrm{PHZ}$ at final concentrations of $0.1-$ $10 \mathrm{mM}$ in PBS at hematocrit of $20 \%, \mathrm{pH} 7.4$, for $45 \mathrm{~min}$ at $37^{\circ} \mathrm{C}$ (7). Parallel control studies were performed by means of incubation of cells in PBS alone at $37^{\circ} \mathrm{C}$ or room temperature.

Materials. Percoll, PHZ, and reagents for determination of ATP, GSH, GOT, SOD, and catalase were all obtained from Sigma Chemical Co. (St. Louis, MO).

Determination of biochemical, morphologic, and physical properties of $R B C$. ATP was determined by measuring NADH oxidation to NAD by glyceraldehyde-3-phosphate dehydrogenase, as reported previously (8). GSH assay was based on reduction of dithiobis-nitrobenzoic acid according to Beutler (9). Hb, hematocrit, and osmotic fragility were determined according to Dacie and Lewis (10). Oxidized $\mathrm{Hb}$ was determined as described by Winterbourn (11): after scanning studies, total oxidized $\mathrm{Hb}$ was determined spectrophotometrically, using a Spectronic 2000 (Bausch and Lomb, Inc., Rochester, NY), at $630 \mathrm{~nm}$. Optic absorbance at this wavelength includes predominantly hemichromes, with addition of methemoglobin and modified porphyrin derivatives, such as choleglobin, previously detected after $\mathrm{PHZ}$ exposure (11). HbF was determined by relative resistance to alkaline medium (12). SOD, catalase, and GOT activities were determined as described by Beutler (9). Density distribution of the cells was determined according to Danon and Marikovsky (13). Morphology was studied after glutaraldehyde fixation and visualization by scanning electron microscopy in JEOL 35 (Tokyo, Japan) (14). The presence of reticulocytes and Heinz bodies was noted after brilliant cresyl blue staining (10).

Adult and newborn cells were exposed to PHZ for Mössbauer 
studies. The exposed cells were frozen immediately and stored in liquid nitrogen before measurement. The recoil-free resonance absorption in the Mössbauer-sensitive nucleus ${ }^{57} \mathrm{Fe}$, present in these cells, was measured by using a conventional Mössbauer spectrometer working in the constant acceleration mode. A 100$\mathrm{mCi}$ radioactive cobalt source $\left({ }^{57} \mathrm{Co}\right)$ and a Harvell proportional counter were used (Harvell, Oxford, England) (15).

Statistics. The data are expressed as mean \pm SEM and were compared by paired $t$ test.

\section{RESULTS}

A preliminary experiment, performed to rule out a direct reaction between GSH and $\mathrm{PHZ}$, revealed negligible reduction in GSH levels after interaction with low to high PHZ concentrations (0.1-40 mM) (data not shown).

Comparison between unseparated neonatal and adult cells. Neonatal and adult cells were studied simultaneously. Hematocrit, $\mathrm{Hb}$, and mean corpuscular $\mathrm{Hb}$ concentration levels were similar to those reported in the literature (2).

$\mathrm{HbF}$ levels in neonatal cells varied between 56 and $85 \%$ of the total $\mathrm{Hb}$, with an average of $68 \pm 8 \%$. These results are similar to those in previous reports on mature newborns.

Density distribution studies confirmed the known heterogeneity of neonatal RBC. The mean ATP level was $5.3 \pm 1.2 \mu \mathrm{mol} /$ $\mathrm{g} \mathrm{Hb}$, higher by $1 \mathrm{SD}$ than the level in adults. Similarly, a high GSH level was found in the newborn cells, $9.0 \mu \mathrm{mol} / \mathrm{g} \mathrm{Hb}$, which is $22 \%$ higher than the level in adults. The levels were higher than expected for a young population of cells. SOD and catalase activities did not differ from those of adult cells (SOD $2150 \pm$ $150 \mathrm{IU} / \mathrm{g} \mathrm{Hb}$ and catalase $13.7 \times 10^{4} \mathrm{IU} / \mathrm{g} \mathrm{Hb}$ ).

PHZ exposure. The results of $\mathrm{PHZ}$ exposure of unseparated populations of adult and newborn cells are presented in Table 1. Initial GSH levels were significantly higher in newborn cells than in adult ones [9.0 and $7.1 \mu \mathrm{mol} / \mathrm{g} \mathrm{Hb}$, respectively $(p<0.01)]$.

Table 1. Effect of PHZ on adult and newborn red cells

\begin{tabular}{lcccc}
\hline & \multicolumn{4}{c}{ Phenylhydrazine } \\
\cline { 2 - 5 } & Untreated & $0.5 \mathrm{mM}$ & $1 \mathrm{mM}$ & $5 \mathrm{mM}$ \\
\hline Adult cells & & & & \\
GSH $(\mu \mathrm{mol} / \mathrm{g} \mathrm{Hb})$ & $7.1 \pm 0.4$ & $5.9 \pm 0.3$ & $4.3 \pm 0.3$ & $3.4 \pm 0.6$ \\
$\%$ & 100 & 83 & 61 & 48 \\
$n$ & 8 & 4 & 7 & 4 \\
Oxidized Hb (\%) & $1.7 \pm 0.3$ & $4.6 \pm 0.2$ & $6.6 \pm 0.6$ & $16.9 \pm 0.8$ \\
$n$ & 5 & 3 & 5 & 5 \\
Newborn cells & & & & \\
GSH $(\mu \mathrm{mol} / \mathrm{g} \mathrm{Hb})$ & $9.0 \pm 0.4^{*}$ & $6.3 \pm 0.1$ & $6.9 \pm 0.6 *$ & $5.6 \pm 0.5^{*}$ \\
$\%$ & 100 & 69 & 77 & 63 \\
$n$ & 8 & 2 & 8 & 8 \\
Oxidized Hb (\%) & $1.5 \pm 0.2$ & $4.2 \pm 0.1$ & $7.6 \pm 1.3$ & $16.5 \pm 1.5$ \\
$n$ & 9 & 5 & 6 & 5 \\
\hline
\end{tabular}

${ }^{*} p<0.01$ (differences between adult and newborn).
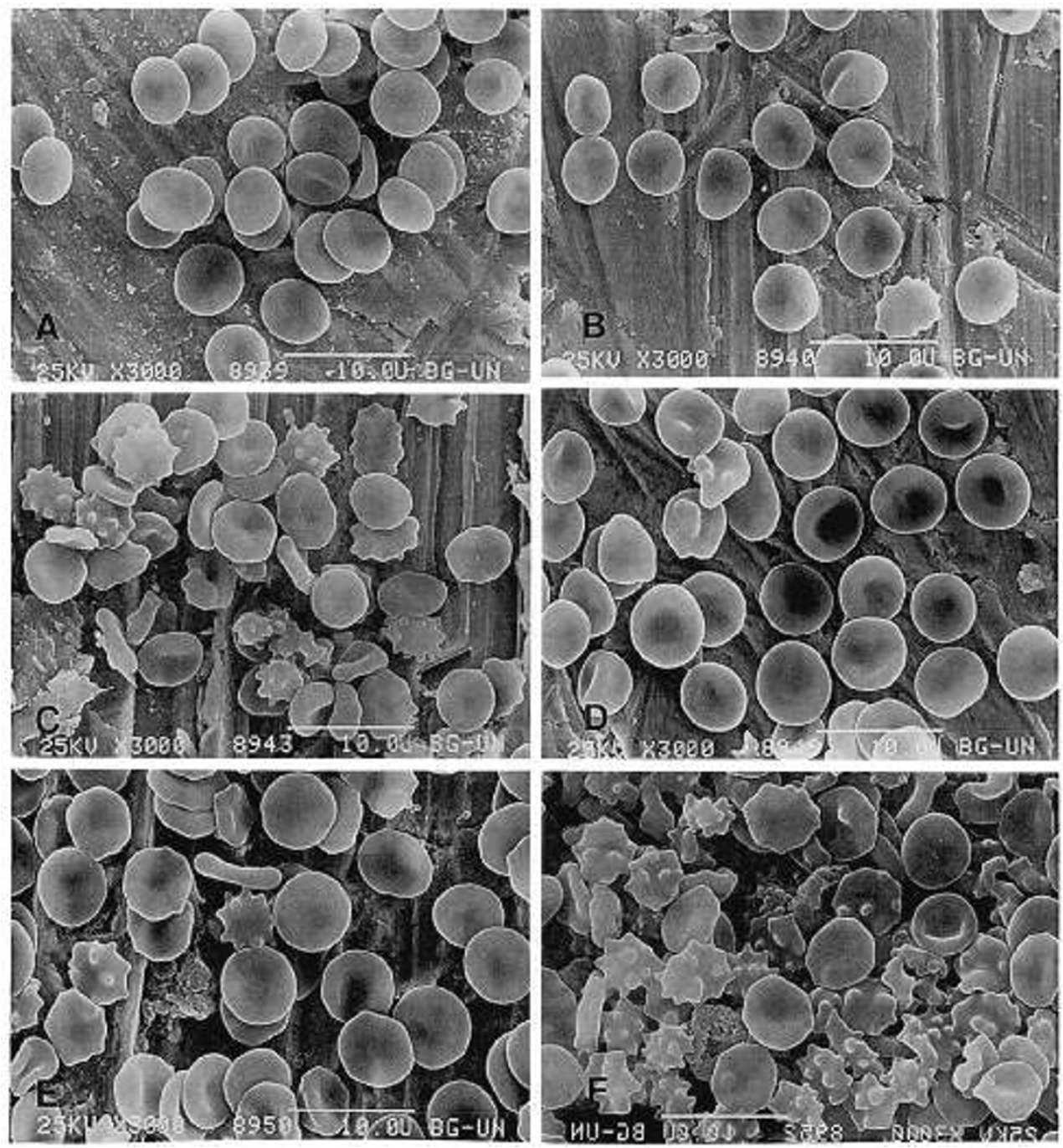

Fig. 1. Morphology of adult and neonatal erythrocytes before and after PHZ exposure. $A$, control adult cells; $B$ and $C$, adult cells treated with 1 and $10 \mathrm{mM} \mathrm{PHZ}$, respectively; $D$, control newborn cells; $E$ and $F$, newborn cells treated with 1 and $10 \mathrm{mM}$ PHZ, respectively. 
Incubation at $37^{\circ} \mathrm{C}$ did not affect GSH levels (data not shown). Exposure to PHZ ( 1 to $5 \mathrm{mM}$ ) decreased GSH levels of adult cells more than those of newborn cells, in both absolute and relative values. Lower concentrations of PHZ $(0.5 \mathrm{mM})$ had a similar effect on both types of cells (70\% reduction). Newborn red cell GSH levels seemed to be higher after exposure to $1 \mathrm{mM}$ $\mathrm{PHZ}$ than to $0.5 \mathrm{mM}$, but this difference is not significant. Despite the difference in the pattern of GSH levels, oxidized $\mathrm{Hb}$ levels increased similarly in both cells. ATP levels were unaffected by PHZ exposure in both cells.

Morphology. Neonatal cells included disc-shaped cells (about $80 \%$ ) as well as echinocytes and stomatocytes. PHZ exposure induced echinocytic changes: exposure to $1 \mathrm{mM}$ caused only mild changes in both neonatal and adult cells. Ten mM PHZ induced $90 \%$ transformation to echinocytes in the neonatal cells, whereas adult cells were more resistant and only $30 \%$ transformed into echinocytes. (Fig. 1).

Mössbauer spectra. The Mössbauer spectra were analyzed by computer fits with a number of quadrupole doublets, where the two lines composing each doublet were assumed to have the same width and intensity. The quadrupole splitting, isomer shift, and line width of each doublet were taken as free parameters. Computer fits to Mössbauer spectra obtained at $90 \mathrm{~K}$ of both neonatal and adult cells under control conditions showed that the spectra were composed of two doublets only, with parameters identical to those of oxy- and deoxyhemoglobin (doublets $a$ and $b$ respectively in Fig. 2). The spectra of samples of neonatal cells exposed to $5 \mathrm{mM} \mathrm{PHZ}$ could be fitted only with three doublets, two of which correspond to oxy- and deoxyhemoglobin as in control samples, and a third, well-defined doublet (Fig. 2,c) shows an isomer shift of $0.44 \pm 0.02 \mathrm{~mm} / \mathrm{s}$ and a quadrupole splitting (eqQ/2) of $0.94 \pm 0.02 \mathrm{~mm} / \mathrm{s}$. At the same $\mathrm{PHZ}$ concentration, this component comprised $20 \%$ of the total absorption area in the spectra of exposed neonatal cells, and did not appear at all in exposed adult cells. Because the absorption area in each doublet in Mössbauer spectra at low temperature is

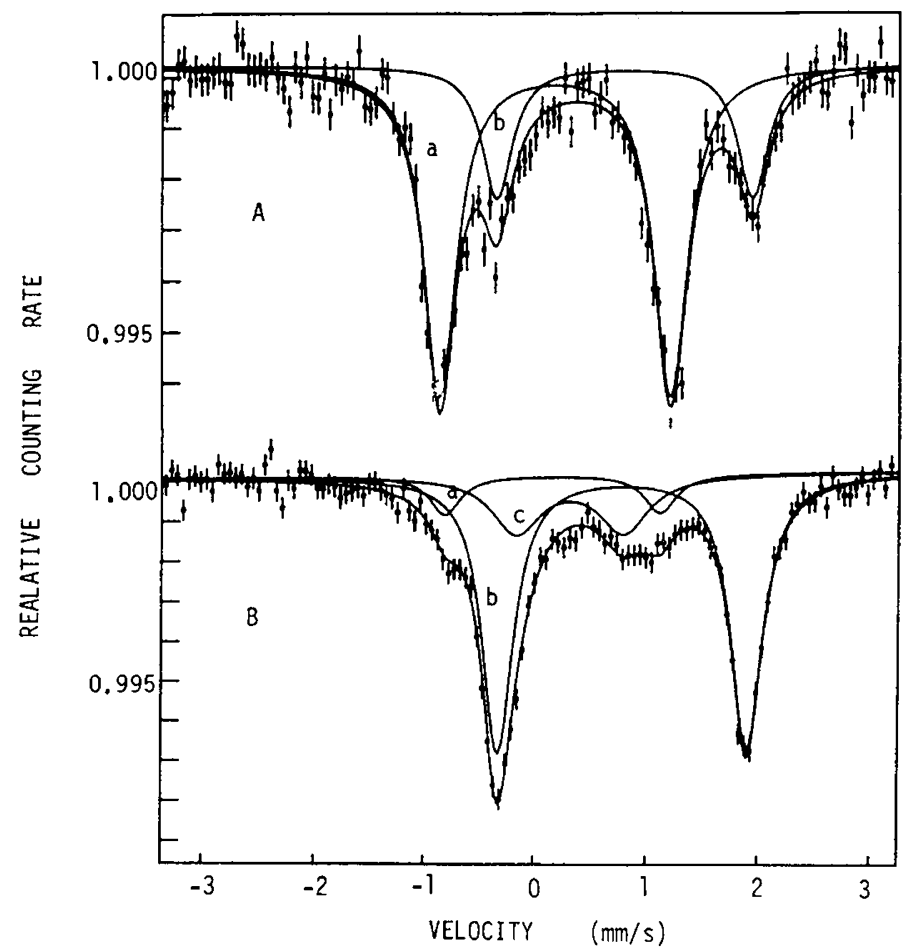

Fig. 2. Mössbauer spectra of adult and neonatal erythrocytes after 5 $\mathrm{mM}$ PHZ exposure. $A$, adult cells; $B$, neonatal cells. The solid lines are least-square computer fits to the spectra. Subspectrum $a$ corresponds to oxyhemoglobin, $b$ to deoxyhemoglobin, and $c$ to a $\mathrm{Hb}$ oxidation product present in neonatal cells only. proportional to the amount of iron in each corresponding compound, about $20 \%$ of the iron in the PHZ-exposed neonatal cells was in a form corresponding to doublet $\mathrm{c}$. The quadrupole splitting and isomer shift of doublet $\mathrm{c}$ are within the region found only in trivalent, high-spin iron compounds. These parameters are different from those found in methemoglobin (16), which gives at $90 \mathrm{~K}$ a relaxation-broadened spectrum and not a welldefined doublet like doublet $c$. The exact identity of the "c component" is not known, but it must represent an oxidation product of $\mathrm{Hb}$, which differs from methemoglobin.

Separated populations. The cells were separated by a Percoll gradient into $10 \%$ light and $10 \%$ heavy cells (Table 2 ). The light layer contained younger cells, as indicated by the higher reticulocyte counts and GOT (Table 2). The separation yielded mean corpuscular $\mathrm{Hb}$ concentration values higher than those in the parallel layers of adult cells; this is in accordance with the data reported by Matovcik et al. (17), using Stractan gradient. The heavy layer was enriched with $\mathrm{HbF}(80 \%$ compared with $58 \%$ in the light layer). This value indicates the presence of older cells in the heavy layer, as is also demonstrated in the report of Gahr et al. (18). Oxidized $\mathrm{Hb}$ and GSH levels did not differ in the heavy and light layers. Similar maintenance of GSH levels in the most dense population has been recently reported by Lane et al. (19). Osmotic fragility increased in the old cells, in accordance with the data of Matovcik et al. (17) (data not shown).

$P H Z$ exposure. Total oxidized $\mathrm{Hb}$, as determined by spectrophotometric analysis, increased with PHZ concentration in a similar pattern in the light and heavy populations of neonatal RBC: $0.5 \mathrm{mM}$ PHZ produced $\mathrm{Hb}$ oxidation of 8.5 and $9.3 \%, 1$ $\mathrm{mM}$ PHZ 13 and $16 \%$, and $10 \mathrm{mM} \mathrm{PHZ} 34$ and 36\%, respectively. Mössbauer spectra studies failed to demonstrate the $\mathrm{c}$ component after mild $\mathrm{PHZ}$ exposure in either population.

Many neonatal cells contained one to two Heinz bodies after exposure to low $\mathrm{PHZ}$ concentration $(0.5 \mathrm{mM})$ in both separated populations, but none were seen in the adult cells.

\section{DISCUSSION}

Several theories have been propounded to explain the short life-span of neonatal erythrocytes, which suggests an acceleration of normal aging processes. Spontaneous endocytosis may cause loss of cell surface and cell deformability, leading to reduced filtrability and destruction by the spleen. The sudden elevation of $\mathrm{PO}_{2}$ after delivery may cause oxidative damage to the cells by free radicals. Previous studies as well as ours show that neonatal erythrocytes have high levels of GSH. It is not clear, however, whether this is advantageous. We suggest that the initial high levels of GSH in neonatal cells were used less efficiently in the reduction of free radicals than those in adult cells after exposure to PHZ. Etukudo et al. (20) obtained similar results with $2 \mathrm{mg} /$ $\mathrm{mL}$ acetylphenylhydrazine without glucose. This limited efficiency may be explained by the low GSH-peroxidase activity in

Table 2. Hematologic parameters in density-separated neonatal erythrocytes

\begin{tabular}{lccc}
\hline & Whole blood & Light layer & Heavy layer \\
\hline $\mathrm{HbF}(\%)$ & $69 \pm 8$ & $58 \pm 3$ & $80 \pm 1^{*}$ \\
$n$ & 31 & 17 & 17 \\
$\mathrm{GOT}(\mathrm{IU} / \mathrm{g} \mathrm{Hb})$ & $6.1 \pm 0.2$ & $9.4 \pm 0.9$ & $4.3 \pm 0.6 \dagger$ \\
$n$ & 2 & 2 & 2 \\
$\mathrm{MCHC}(\%) \ddagger$ & $32.2 \pm 3.2$ & $28.6 \pm 0.9$ & $37.3 \pm 1.0^{*}$ \\
$n$ & 18 & 18 & 18 \\
$\mathrm{GSH}(\mu \mathrm{mol} / \mathrm{g} \mathrm{Hb})$ & $9.04 \pm 0.4$ & $8.34 \pm 0.5$ & $9.45 \pm 0.7$ \\
$n$ & 30 & 4 & 4 \\
Oxidized $\mathrm{Hb}(\%)$ & $1.5 \pm 0.2$ & $1.3 \pm 0.2$ & $1.2 \pm 0.4$ \\
$n$ & 15 & 3 & 3 \\
\hline
\end{tabular}

$* p<0.001$ (difference between light and heavy layer).

$\dagger p<0.05$ (difference between light and heavy layer).

$\ddagger \mathrm{MCHC}$, mean corpuscular $\mathrm{Hb}$ concentration. 
neonatal erythrocytes (2). In contrast to this view, Oski and Komazawa (21) argued that GSH levels were less stable in the cells of the newborn, i.e. GSH easily oxidized.

The stronger tendency of neonatal erythrocytes for $\mathrm{Hb}$ oxidation by oxidative stress could be explained by higher tendency to denaturation and oxidation of $\operatorname{HbF}(1,22)$. In addition, the activity of NADH-dependent methemoglobin reductase is about $50 \%$ less in neonatal cells. This low activity limits the methemoglobin reduction to functioning $\mathrm{Hb}$.

Morphologic changes, i.e. membrane loss and echinocyte production, that may be caused by oxidative stress have been considered as possible causes of senescence. PHZ causes more morphologic changes (including echinocytosis) in neonatal RBC than in adult RBC. It is known that PHZ causes cross-linking between spectrin molecules, which may result in reduced red cell deformability (23). Wagner et al. (24) have suggested that echinocyte formation is a step in exocytosis. Neonatal erythrocytes have a tendency toward endocytosis, which may also cause membrane loss.

We observed marked morphologic changes only at high concentrations of PHZ (10 mM). Reinhart et al. (25) argued that it is not reasonable for oxidative stress to play a major role in cell destruction inasmuch as reduced filtrability was observed only after severe oxidative stress (10 mM PHZ), much more extreme than physiologic conditions. In this study, we attempted to measure the magnitude of oxidative changes in the cells by measuring the remaining GSH levels and the production of oxidized $\mathrm{Hb}$. Rachmilewitz (26) has shown that the methemoglobin produced may be further oxidized to hemichromes. Because methemoglobin, oxyhemoglobin, and hemichromes have similar absorption spectra, their separate contribution to absorption at a certain wavelength cannot be identified. For this purpose, electron paramagnetic resonance may be used (27), as well as Mössbauer spectroscopy.

Our study shows that in PHZ-treated neonatal cells a new iron-containing species is formed. Because these Mössbauer parameters are so similar to those found in hemin imidazole (28) or in the acid form of metmyoglobin and cytochrome $\mathrm{C}$ peroxidase (16), it is reasonable to assume that iron coordination in the component is similar to that found in the compounds mentioned. The absence of this component in adult cells indicates that the concentration of this unidentified oxidized $\mathrm{Hb}$ in these cells is less than $2 \%$.

To isolate populations enriched with old $R B C$, we separated light and heavy layers on a Percoll gradient. The heavy layer contained $20 \%$ more $\mathrm{HbF}$ than the light one, proving that the former was enriched with old cells. This layer was also osmotically more fragile than the light layer and whole blood, as has been demonstrated with other gradient separations (17). We did not find any significant difference between light and heavy layers in oxidized $\mathrm{Hb}$ and $\mathrm{GSH}$ levels, nor were significant differences found after exposure to PHZ. It is possible that the differences are minor and therefore hard to define in enriched populations.

Recently, Jain (22) reviewed the current data for oxidative susceptibility of the neonatal erythrocyte and theorized that the increased production of oxygen radicals (due to $\mathrm{HbF}$ ) and the lower activities of antioxidant defense mechanisms lead to oxidative damage in the membrane and thereby to increased phagocytosis and shortened survival.

In summary, a well-defined oxidized $\mathrm{Hb}$ that differs from methemoglobin was demonstrated in neonatal erythrocytes after oxidative stress. These findings confirm the increased sensitivity of these neonatal cells to oxidation and emphasize the role of $\mathrm{HbF}$. However, the correlation between this sensitivity and shortened life-span of these cells is not yet clear.

\section{REFERENCES}

1. Bunn HF, Forget BG 1986 Hemoglobin: Molecular, Genetic, and Clinical Aspects. WB Saunders, Philadelphia, pp 61-90

2. Naiman JL, Oski EA 1982 Hematologic Problems in the Newborn, 3rd Ed. WB Saunders, Philadelphia

3. Matovcik LM, Menzer WC 1985 The membrane of the human neonatal red cell. In: Schrier SL (ed) Clinics in Hematology. Saunders, London, pp 203211

4. Low PS, Waugh SM, Zinke K, Drenckhan D 1985 The role of hemoglobin denaturation and band 3 clustering in red blood cell aging. Science 227:531533

5. Schlueter K, Drenkhahn D 1986 Co-clustering of denatured hemoglobin with band 3 : its role in binding of autoantibodies against band 3 to abnormal and aged erythrocytes. Proc Natl Acad Sci USA 83:6137-6141

6. Ellory JC, Young JD 1982 Red cell membrane: a methodological approach Academic Press, London, pp 1-11

7. Jandl JH, Engel LK, Allen DW 1960 Oxidative hemolysis and precipitation of hemoglobin. Heinz body anemias as an acceleration of red cell aging. J Clin Invest 39:1818-1836

8. Meyerstein N, Mazor D, Dvilansky A 1970 Changes in agglomeration of human red blood cells in liquid storage in CPD media. Transfusion 17:115122

9. Beutler E 1984 Red Cell Metabolism: A Manual of Biochemical Methods, 3rd Ed. Grune and Stratton, Orlando, FL

10. Dacie JV, Lewis SM 1984 Practical Haematology, 6th Ed. Churchill Livingstone, Edinburgh

11. Winterbourn CC 1985 Free radical production and oxidative reactions of hemoglobin. Environ Health Perspect 64:321-330

12. Atwater J, Erslev AJ 1972 Fetal hemoglobin-alkali denaturation test. In: Williams AJ, Beutler E, Erslev AJ, Rundles RW (eds) Hematology. McGraw Hill, New York, pp 1369-1370

13. Danon D, Marikovsky Y 1964 Determination of density distribution of red cell population. J Lab Clin Med 64:668-674

14. Meyerstein N, Mazor D, Etzion Z, Yagil R 1978 Permeability of erythrocytes to glycerol and its acylated derivatives in the camel and dog. Comp Biochem Physiol 26:261-265

15. Bauminger ER, Cohen SG, Ofer S, Rachmilewitz EA 1979 Quantitative studies of ferritin-like iron in erythrocytes of thalassemic, sickle cell anemia and Hemoglobin Hammersmith with Mössbauer spectroscopy. Proc Natl Acad Sci USA 76:939-943

16. Lang G 1970 Mössbauer spectroscopy of heme proteins. Quart Rev Biophys $3: 1-60$

17. Matovcik LM, Chiu D, Lubin B, Menzer WC, Lane PA, Mohandas N, Schrier SL 1986 The aging process of human neonatal erythrocytes. Pediatr Res 20:1091-1096

18. Gahr M, Meves H, Schroeter W 1979 Fetal properties in red blood cells of newborn infants. Pediatr Res 13:1231-1236

19. Lane PA, Galili U, Iarocci TA, Shew RL, Menzer WC 1988 Cellular dehydration and immunoglobulin binding in senescent neonatal erythrocytes. Pediatr Res 23:288-292

20. Etukudo HM, Ramachandran M, Iyer XN 1984 Methemoglobin formation and glutathione disappearance in cord blood red cells exposed to acetylphenylhydrazine. Clin Chim Acta 138:135-139

21. Oski FA, Komazawa M 1974 Metabolism of the erythrocyte of the newborn infant. Semin Hematol 12:209-211

22. Jain SK 1989 The neonatal erythrocyte and its oxidative susceptibility. Semin Hematol 26:286-300

23. Vielsen B, Nielsen H 1984 Reaction of phenylhydrazine with erythrocytes. Biochem Pharmacol 33:2739-2748

24. Wagner GM, Chin DTY, Yee MC, Lubin BH 1986 Red cell vesiculation-a common membrane physiologic event. J Lab Clin Med 108:315-324

25. Reinhart WH, Sung LA, Chien S 1983 Quantitative relationship between Heinz body formation and red blood cell deformability. Blood 68:13761383

26. Rachmilewitz EA 1974 Denaturation of the normal and abnormal hemoglobin molecule. Semin Hematol 11:441-462

27. Rachmilewitz EA, Peisach J, Blumberg WE 1971 Studies on the stability of oxyhemoglobin and its constituient chains and derivatives. J Biochem 246:3356-3361

28. Epstein LM, Straub DK, Maricondi C 1967 Mössbauer spectra of some porphyrin complexes with pyridine, piperidine, and imidazol. Inorg Chem $6: 1720-1724$ 